\title{
PEKERJAAN SOSIAL KOMUNITAS BERBASIS LINGKUNGAN (COMMUNITY SOCIAL WORK BASED ON ENVIRONMENTAL)
}

\author{
Oleh: \\ Purwowibowo $^{1}$, Syech Hariyono ${ }^{2}$, Djoko Wahyudi ${ }^{3}$ \\ 1. Dosen Jurusan Ilmu Kesejahteraan Sosial FISIP Universitas Jember \\ 2. Dosen Jurusan Ilmu Kesejahteraan Sosial FISIP Universitas Jember \\ 3. Dosen Jurusan Ilmu Kesejahteraan Sosial FISIP Universitas Jember
}

Email:

(poerwowibowo@yahoo.co.id, syech_hariyono@yahoo.com, wahyuqq@gmail.com)

\begin{abstract}
Abstrak
Artikel ini membahas tentang pentingnya faktor lingkungan dalam mendukung Sistem Usaha Kesejahteraan Sosial. Selama ini, praktik usaha kesejahteraan sosial masih dalam kerangka baku, yang hanya menggunakan pendekatan case work, group work, community organization dan community development. Sekarang telah disadari oleh para pakar kesejahteraan sosial dan pekerjaan sosial bahwa masalah kesejahteraan sosial juga berasal dari degradasi lingkungan.

Agar dapat berperan aktif dan positif ahli kesejahteraan sosial dan pekerja sosial dalam melakukan intervensi komunitas, maka perlu menambah pengetahuannya tentang ekologi dan lingkungan agar mampu melakukan intervensi dengan baik. Metode intervensi ini berbasis lingkungan, sehingga dalam mengatasi masalah sosial pekerja sosial bisa melakukan pembelaan terhadap korban kerusakan lingkungan dan mampu berperan aktif dalam memberikan kesadaran masyarakat tentang pentingnya unsure lingkungan sebagai bagian hidup manusia.

Dengan perkembangan ini, pekerja sosial dan ahli di bidang kesejahteraan sosial harus memperlajari ilmu-ilmu terkait lingkungan agar mampu melakukan praktik pekerjaan sosialnya dengan baik. Model pekerja sosial demikian dapat disebut sebagai 'pekerja sosial hijau' atau 'green social worker'.
\end{abstract}

Keywords: Lingkungan, SUKS, pekerja sosial, Green Social Worker

\section{PENDAHULUAN}

Sepuluh tahun terakhir ini Sistem Usaha Kesejahteraan Sosial (SUKS) terus berkembang tidak hanya bersifat charity dan philantrophy ${ }^{23}$, tetapi juga ada SUKS yang berbasis bisnis atau interprise. ${ }^{24}$ Di awal masuknya, usaha kesejahteraan sosial di Indonesia didominasi oleh sistem yang dilandasi oleh rasa belas kasihan dan amal tersebut. Namun perkembangkan sekarang ini,

${ }^{23}$ Lihat, Friedlander, W. (1974) Introduction to Social Welfare. Prentice Hall. Inc. New Jersey. ; Zastro, C. (1996). Introduction to Social Work and Social Welfare. Brook / Cole Publishing Company. usaha kesejahteraan sosial sudah mengarah kepada usaha yang bersifat profit atau menguntungkan. Memang usaha yang berbasis pada charity dan philantrophy tidak ditinggalkan. Kecenderungan usaha yang berorientasi bisnis untuk mencari untung ini telah merambah kepada semua usaha kesejahteraan sosial - yang dulunya tidak terpikirkan adanya keuntungan tersebut bagi usaha di bidang ini. Mencari keuntungan dari

\footnotetext{
${ }^{24}$ Purwowibowo (2014) Peran Pekerja Sosial Dalam Sistem Usaha Kesejahteraan Sosial di Era Millenium. Share. Social Work Journal. Vol 4 No 2. p $198-210$.
} 
usaha bisnis bukan milik bidang ekonomi saja tetapi sekarang ini usaha-usaha kesejahteraan sosial dilandasi dengan mencari keuntungan miskipun nilai sosial dari pekerjaan sosial tidak ditinggalkan.

Pekerja sosial generasi baru di era millennium ini, menyadari sangat pentingnya lingkungan dalam merumuskan kerangka teoritis dan praktis terkait dengan kesejahteraan sosial. Dimulai sejak tahun 80an sampai 90-an, asosiasi pekerja sosial Amerika Utara dan Eropa mulai memperhatikan menurunnya kualitas lingkungan hidup mereka. Para ahli kesejahteraan sosial dan pekerjaan sosial mulai lebih aktif di dalam memainkan perannya, khususnya membahas masalah kesadaran ekologi atau lingkungan hidup. Sejak saat itu, para pakar mulai ikut ambil bagian dalam menentukan kebijakan terkait dengan isu tentang kerusakan lingkungan. ${ }^{25}$

\section{Lingkungan hidup, secara umum} belum banyak diperhatikan oleh ahli kesejahteraan sosial dan pekerja sosial. Hal ini tampak dari intervensi yang dilakukan terhadap masalah sosial di tengah masyarakat belum memperhatikan aspek lingkungan. Faktor lingkungan, baru disadari oleh para ahli di bidang kesejahteraan sosial setelah para pakar di bidang ini membahas dampak kerusakan lingkungan terhadap masyarakat. Kecelakaan reaktor Chernobil di Rusia pada tahun 1986, telah menimbulkan dampak negatif yang mengerikan terhadap penderitaan, kesengsaraan, dan kualitas kehidupan manusia. Dengan peristiwa tersebut kemudian para ahli menyadari bahwa kerusakan lingkungan dapat mempengaruhi kehidupan dan kesejahteraan manusia. ${ }^{26}$

Selain itu, sekarang ini perubahan iklim (climate change) misalnya menjadi isu

\footnotetext{
${ }^{25}$ Dominelli, L. (2012). Green Social Work. From Environmental Crisis to EnvironmentalJustice. Cambridge: Policy press.

${ }^{26}$ Gray, M. Et al. (2013) Environmental Social Work. London: Routladge.

27 Lihat: Gray, M. (2005). Dilemmas of International Social Work Paradoxial Processes in Indigenous, Universalism and Imperialism.
}

penting lainnya bagi seluruh kehidupan di muka bumi. Para pakar kesejahteraan sosial dan pekerjaan sosial juga mulai membahas hal tersebut terkait dengan kesejahteraan sosial. Para pakar sebelumnya tidak tertarik sama sekali dengan isu ini. Namun, belakangan ini pertemuan-pertemuan mereka banyak juga membahas perubahan iklim dan juga mencari solusi yang dapat digunakan untuk mengurangi isu tersebut. Dengan pentingnya isu lingkungan kemudian menjadi mainstreams dalam pertemuan pakar kesejahteraan sosial dan pekerjaan sosial sehingga banyak tulisan dalam jurnal internasional terkait dengan penyelesaikan masalah sosial berbasis lingkungan.

\section{PERUBAHAN IKLIM DAN PEKERJAAN SOSIAL KOMUNITAS}

Pada abad millenium ini, masyarakat menjadi semakin 'meng-global', di mana batas wilayah administrasi, sosial-budaya menjadi semakin tipis. Bahkan, batas demikian terus sulit dikenali karena masyarakat global menjadi suatu sistem tertentu. Masyarakat global merupakan suatu sistem, baik ekonomi, sosial-budaya, hubungan internasional, politik, dan international social work $^{27}$, menjadi suatu kesatuan yang tidak bisa lagi dipisahkan satu dengan yang lain.

Perubahan sosial yang terus berlangsung saat ini akan terus mengalami perubahan di masa datang dan mungkin nanti perubahannya menjadi semakin dahsyat. Dengan keadaan demikian para pakar menyarankan kita harus menggunakan paradigma baru yakni 'paradigma lingkungan'. ${ }^{28}$ Paradigma ini sesungguhnya menentang adanya asumsi di masyarakat modern yang berbasis konsumtif dan jasa.

International Journal of Social Welfare. Vol 14 Issue 3 p $231-238$.

28 Luckett, Sidney (2004). Environmental Paradigms, Biodiversity Conservation, and Critical System Thinking. Systemic Practice and Action Research. Vol 17 Issue 5 p 511 534. 
Berlandaskan paradigma lingkungan, maka secara berturut-turut asosiasi pekerja sosial di berbagai belahan dunia berupaya melakukan gerakan melindungi lingkungan demi kesejahteraan masyarakat dan kehidupan manusia. Manusia harus menyadari bahwa hidupnya merupakan bagian dari ekosistem lingkungan dan lingkungan harus dikonservasi keragamannya sehingga dapat menopang sistem usaha kesejahteraan sosial.

Menurut Dominelli ${ }^{29}$, peran pekerja sosial atau ahli dibidang kesejahteraan sosial sesungguhnya mempunyai peran penting terkait dengan isu lingkungan. Ahli di bidang ini dapat memberikan pemahaman kepada orang-orang mengenai isu perubahan iklim terhadap kehidupan dan demikian pula kehidupan manusia dapat merusak atau mempengaruhi kondisi lingkungan. Selain itu, pekerja sosial juga mendorong masyarakat luas dalam melakukan penggunaan dan mengkonsumsi energiatau penggunaan energi secara berkelanjutan. Dalam hal ini, peran ahli di bidang kesejahteraan sosial dan pekerja sosial profesional dapat membolisasi masyarakat dalam melakukan perlindungan terhadap kelestarian lingkungan demi masa depan mereka sendiri dan generasi mendatang. Keterlibatan mereka dapat dilakukan melalui pekerjaan sosial komunitas dan ikut merancang penyelesaian masalah dengan menggunakan model rumah kaca (green house model) yakni mengurangi emisi karbon, melakukan advokasi terhadap masyarakat agar peduli untuk melakukan konservasi dan juga menjaga kelestarian lingkungan.

Perubahan iklim merupakan isu internasional yang penting bagi pekerja sosial dan sarjana kesejahteraan sosial. Hal ini terkait dengan dampak perubahan iklim (Climate Change Effects) ${ }^{30}$ sudah banyak dirasakan oleh kehidupan manusia di berbagai bidang, terutama menyangkut masalah kesehatan

${ }^{29}$ Dominelli, L. (2011). Climate Change: Social Workers' role and contributions to policy debates and interventions. International Journal of Social Welfare. ISSN 1369-6866. DOI: 10,111/j.1468-2397.2011,00795, X. Int J Soc Welfare 2011: 20; 430-438 manusia dan kesejahteraannya. Perubahan iklim sesungguhnya dipengaruhi oleh penggunaan energi (fosil fuel) yang berlebihan dan tidak berkelanjutan. Bahkan, sekarang ini belum ada pemikiran tentang masa depan umat manusia terkait dengan keberadaanberbagai energi, khususnya energi yang dapat habis (non-renewable resources). Masalah kesehatan manusia dan generasi mendatang sangat terkait dengan sakit mata (katarak), kanker kulit, dan berbagai penyakit lain yang dapat memperburuk kualitas hidup dan kesejahteraan manusia terkait dengan dampak dari perubahan iklim tersebut. Selain itu, perubahan iklim juga mempengaruhi perubahan musim, curah hujan, dan angin sehingga berdampak negatif terhadap pertanian dan produksi pangan. Kebutuhan akan pangan menjadi masalah serius karena musim panen bisa gagal karena berbagai tanaman pangan yang membutuhkan air tidak tersedia dengan cukup mudah didapatkan.

Di antara dampak-dampak negatif tersebut dapat mengurangi atau menekan kesejahteraan hidup masnuia atau dengan kata lain menekan kualitas hidup manusia. Misalnya terjadi kesengsaraan, penderitaan, kehilangan kesempatan kerja, dan bahkan dapat terusir dari kehidupan di tanah kelahirannya karena tanahnya tidak bisa memberikan kehidupan yang dibutuhkan sebagaimana terjadi di wilayah Chernobil, Rusia.

\section{DAMPAK RUMAH KACA (GREEN HOUSE EFFECT)}

Dampak rumah kaca sangat komplek, di antaranya emisi karbon dioksida yang dibakar menyembur ke angkasa, hal ini terkait dengan proses industrialisasi dan rumah tangga yang dapat berakibat meningkatnya suhu atau temperatur di permukaan bumi. ${ }^{31}$ Penyumbang

\footnotetext{
${ }^{30}$ McMichael, A. J. Et al. (2003). Climate Change and Human Health, Risk and Responses. WHO Library Cataloguing-in-Publication Data.

${ }^{31}$ Cox, P. M. Et al. (2000). Accelaration of Global Warming Due to Carbon Cycle Feedbacks in a
} 
terjadinya dampak rumah kaca tersebut bukan hanya industri maju tetapi juga negara sedang berkembang, dan bahkan masyarakat, rumah tangga dapat menyumbang terjadinya perubahan iklim. Oleh karena itu, program pembangunan yang harus dijalankan sekarang ini harus menyertakan keberadaan dan keberlanjutan/kelestarian lingkungan, terutama partisipasi masyarakat dalam usaha melestarikan keberadaan lingkungan.

Melihat kenyataan bahwa perubahan iklim sudah di depan mata dalam kehidupan manusia, maka ahli kesejahteraan sosial, pekerja sosial profesional, dan semua orang (masyarakat secara luas) harus bertindak untuk mengurangi penyebab terjadinya perubahan iklim tersebut. Hal ini terkait dengan perubahan iklim dapat menekan kehidupan manusia dan memperburuk kualitas penghidupan serta kesejahteraan masyarakat. Bahkan, perubahan iklim dapat mengakibatkan kesengsaraan dan penderitaan hidup manusia yang terus menerus sampai seseorang meninggal dunia.

\section{PERAN AHLI KESEJAHTERAAN SOSIAL DAN PEKERJA SOSIAL DALAM INTERVENSI KOMUNITAS}

Perubahan iklim sangat erat hubungannya dengan kesejahteraan sosial masyarakat. Hal ini terkait dengan ketidak adilan sosial, kesengsasaraan, penderitaan manusiayang ditimbulkan dari dampak perubahan iklim. Dampak negatif dan dampak sosial dari perubahan iklim harus direspon oleh ahli di bidang kesejahteraan sosial dan pekerja sosial komunitas. ${ }^{32}$ Guna mewujudkan hal tersebut para ahli mempunyai peran penting untuk mewujudkan dan mengembangkan suatu sistem usaha kesejahteraan sosial dalam kerangka mempertahankan kelangsungan hidup manusia. Dengan demikian pekerja

Coupled Climate Model. Nature: International Weekly Journal of Science.

32 Delgado, M. (2000). Community Social Work Practice in anUrban Context: The Potentialof a Capacity-Enhancement sosial dan ahli di bidang kesejahteraan sosial harus melibatkan diri dan berperan aktif dalam membahas isu perubahan iklim pada umumnya dan mencari solusi pemecahan masalah yang dilandasi dengan potensi lingkungan.

Para ahli kesejahteraan sosial dan pekerja sosial profesional harus mempelajari berbagai ilmu dibalik perubahan iklim tersebut. seperti misalnya, ilmu ekologi, ilmu lingkungan, biologi, dan ilmu-ilmu lain yang terkait dengan perubahan iklim harus dipelajari untuk dapat memahami perubahan iklim terkait masalah sosial yang ada. Selain itu, para pakar di bidang ini juga harus mampu mengkritisi kebijakan, mengembangkan kesadaran individu dan komunitas dalam mengurangi penyebab terjadinya perubahan iklim. Selain itu, mereka juga harus mampu mencari jalan keluar tentang keterbatasan sumber daya alam dan mampu menyarankan masyarakat agar mau menggunakan berbagai sumber sumber daya alam yang ada secara efektif dan efisien sehingga keberlangsungannya menjadi lebih panjang.

Jadi ahli kesejahteraan sosial dan pekerja sosial harus membangun kemampuan dan keahliannya sehingga mampu melakukan intervensikomunitasnya dengan baik. Dengan menggunakan berbagai basis ilmu pengetahuan terkait dengan lingkungan dan ekologi ahli di bidang ini mampu memberikan solusi sosial terkait dengan perubahan iklim. Misalnya memberikan intervensi sosial berupa pemahaman pentingnya keberadaan lingkungan hidup lestari yang dapat menopang kehidupan dan kesejahteraan manusia.

Selain itu, para ahli kesejahteraan sosial dan pekerja sosial profesional mempunyai peran penting terutama terkait dengan sikap-sikap yang ditunjukkan oleh masyarakat terhadap lingkungannya.

Pertama, sikap yang disebut dengan 'Positive-greens', yakni suatu konsep yang

Perspective. England: Oxford University Press. 
sedapat mungkin mengurangi tindakan manusia untuk sekecil-kecilnya mengakibatkan terjadinya kerusakan lingkungan. Selain itu, semua kegiatan manusia harus berdampak positif terhadap kehidupan manusia dan berusaha untuk menghadirkan atau mengeliminasi terjadinya dampak negatif terhadap kehidupan manusia. Sikap ini harus diupayakan oleh ahli kesejahteraan sosial dan pekerja sosial agar semua orang menyadari bahwa semua tindakannya harus berdampak positif kepada lingkungan dan kehidupan manusia dan bukan sebaliknya. Contohnya, menaman pohon, membersihkan lingkungan hidup di sekitarnya dan melakukan penghematan sumber daya, melakukan penggunaan ulang.

Kedua, sikap yang disebut dengan 'Waste-watchers'. Sikap atau tindakan ini terkait dengan suatu perilaku yang sedapat mungkin melakukan daur ulang dari apa yang digunakan manusia. sikap ini sangat terkait dengan keberadaan sampah yang cukup banyak jumlahnya. Dengan mendaur ulang berarti dapat mengurangi jumlah sampah yang ada. Ahli kesejahteraan sosial dan pekerja sosial profesional dapat memberikan dorongan dan semangat kepada masyarakat tentang pentingnya mendaur ulang limbah atau sampah yang dihasilkan.

Ketiga, sikap yang disebut dengan 'Concerns-consumers'. Sikap ini terkait dengan tindakan di dalam mengurangi beban lingkungan (carrying capacity). Keberadaan lingkungan dan sumber dayanya mempunyai keterbatasan di dalam mendukung kehidupan manusia di sekitarnya. Oleh karena itu, ahli di bidang kesejahteraan sosial dan pekerja sosial profesionaldapat melakukan tindakan sebanyak mungkin, tetapi apa yang dilakukannya tersebut tidak boleh melampaui batas carrying capacity lingkungan.

Keempat, sikap yang terkait dengan 'Side line supporters'. Sikap ini terkait dengan kesadaran yang harus dimiliki oleh manusia bahwa kerusakan lingkungan dan perubahan iklim sesungguhnya masalah penting. Namun, sikap yang ditunjukkan justru sebaliknya yakni tindakan yang mengakui bahwa perubahan iklim penting, tetapi menolak melakukan perubahan gaya hidup. Masih senang hidup secara konsumtif menghabiskan berbagai sumber daya untuk memenuhi kesenangan hidupnya.

Kelima, yaitu sutu sikap yang disebut dengan 'Stalled Starters'. Sikap ini sama dengan cuek terhadap kondisi lingkungan di sekitarnya. Mereka tidak tahu menahu tentang perubahan iklim dan yang penting hidup makmur. Menurut mereka yang pentinga adalah hidup sejahtera tetapi tidak peduli untuk mengurangi terjadi perubahan iklim yang sedang terjadi. Oleh karena itu, ahli di bidang kesejahteraan sosial dan pekerjaan sosial dapat memberikan kesadaran bagi mereka tentang masalah perubahan iklim ini terkait dengan kehidupan manusia secara keseluruhan.

Keenam, adalah sikap yang disebut dengan 'Honestly disengaged'. Orang dengan sikap ini sesungguhnya tidak peduli dengan isu perubahan iklim. Mereka menganggap bahwa perubahan iklim tidak ada kaitannya dengan kehidupan mereka. Meskipun hal ini tidak merugikan lingkungan dan masyarakat tetapi sikap demikian perlu juga disadarkan oleh ahli kesejahteraan sosial dan pekerja sosial profesional.

Studi kasus di Argentina, dapat dijadikan contoh sikap yang baik terhadap perubahan iklim dan kondisi lingkungan sekitarnya. Di negara tersebut ada suatu masyarakat lokal yang telah lama hidup dalam ekosistem yang lestari karena perilaku kehidupannya telah selaras dengan lingkungannya. Dalam menjalani kehidupannya mereka mengandalkan sumber daya lingkungan di sekitarnya untuk mendukung kehidupannya. Dengan menggunakan energi berkelanjutan mereka dalam memasak, memanaskan rumahnya dengan menebang sebagian kayu di hutan untuk memenuhi kebutuhan energi tersebut. Dengan model demikian produksi energi dapat terbarukan terus menerus dan berarti mereka dapat mengurangi dampak perubahan iklim di wilayah argentina. Pekerja sosial dapat belajar dari pengalaman salah satu suku di Argentina tersebut kemudian diseminasikan ke tempat 
lain. Apa yang dilakukan suku tersebut merupakan kearifan lokal dalam mengurangi sumber penyebab timbulnya perubahan iklim, yaitu menggunakan sumber daya terbarukan dan lestari.

Kemudian juga ada studi kasus di Inggris, salah satu keterlibatan ahli kesejahteraan sosial dan pekerja sosial dalam mengurangi penyebab terjadinya sumber perubahan iklim adalah dengan melibatkan banyak stakeholder di dalam merancang penggunaan energi berkelanjutan bagi masyarakat miskin di Gilesgate tersebut. Di wilayah tersebut di dalam menggunakan sumber daya yang ada untuk menghasilkan energi terbarukan dan berkelanjutan sehingga di kawasan tersebut tidak pernah mengalami krisis energi. Ahli kesejahteraan sosial dan pekerja sosial komunitas dapat melibatkan banyak stakeholder dan para ahli untuk merancang, membangun, melaksanakan konsep desa hijau sekaligus mengevaluasi semua kegiatannya.

Ahli kesejahteraan sosial dan pekerja sosial dapat menyadarkan semua lapisan masyarakat tentang pentingnya penggunaan energi yang irit, di rumah tangga maupun di area publik. Terkadang penyadaran secara individual kurang efisien. Oleh karena itu, ahli kesejahteraan sosial dan pekerja sosial juga harus memperhatikan langkah atau tindakan yang bersifat kolektif/bersama dalam mengurangi masalah global tersebut. Hal tersebut dapat dilakukan melalui suatu kebijakan tertentu oleh pemerintah. Para ahli dapat memberikan masukannya konstruktif tentang peraturan atau UU yang terkait dengan lingkungan pada umumnya dan juga perubahan iklim khususnya.

Oleh karena itu, secara spesifik dapat dikemukakan peran ahli kesejahteraan sosial dan pekerja sosial profesional komunitas sebagai berikut:

- Meningkatkan kesadaran masyarakat agar dapat mengurangi dampak rumah kaca atau perubahan iklim.

- Melakukan lobi, mulai dari masyarakat lokal sampai masyarakat internasional di dalam menggunakan energi terbarukan dengan melakukan pembelaan melalui kebijakan publik dengan berbasis teknologi hijau;

- Mobilisasi masyarakat dalam mengurangi emisi karbon dalam semua kehidupannya;

- Melakukan dialog dengan pembuat kebijakan, mulai dari lokal, nasional, dan internasional;

- Mengembangkan kurikulum di setiap perguruan tinggi dan dunia pendidikan pada umumnya untuk peduli mengenai perubahan iklim dengan melakukan intervensi dengan membangun dan mendorong individu dan masyarakat menyadari isu perubahan iklim.

\section{KESIMPULAN}

Persoalan atau isu mengenai perubahan iklim sangat bermanfaat bagi ahli kesejahteraan sosial dan pekerja sosial untuk melakukan intervensinya. Perannya sangat penting terutama di dalam mengurangi emisi karbon, mendorong masyarakat untuk menggunakan energi bersih dan melindungi masyarakat dari dampak negatif perubahan iklim dengan menguatkan induvidu dan komunitas serta membantu masyarakat mendapatkan energi yang berbasis teknologi ramah lingkungan. Perannya menjadi terdepan di dalam menginisiasi penggunaan energi yang efisien yang dapat mengurangi sumbangannya terhadap timbulnya perubahan iklim.

\section{DAFTAR PUSTAKA}

Cox, P. M. Et al. (2000). Accelaration of Global Warming Due to Carbon Cycle Feedbacks in a Coupled Climate Model. Nature: International Weekly Journal of Science.

Delgado, M. (2000). Community Social Work Practice in anUrban Context: The Potentialof a Capacity-Enhancement Perspective. England: Oxford University Press.

Dominelli, L. (2011). Climate Change: Social Workers' Role and Contributions to 


\begin{tabular}{|c|c|c|c|c|}
\hline $\begin{array}{c}\text { 118SHARE: SOCIAL WORK } \\
\text { JURNAL }\end{array}$ & VOLUME: 7 & NOMOR: 1 & HALAMAN: 1 - 129 & $\begin{array}{l}\text { ISSN:2339 -0042 }(p) \\
\text { ISSN: 2528-1577 }(e)\end{array}$ \\
\hline
\end{tabular}

Policy Debates and Interventions. International Journal of Social Welfare. ISSN 1369-6866. DOI: 10,111/j.1468-2397.2011,00795, X. Int J Soc Welfare 2011: 20; 430-438. ....(2012). Green Social Work. From

Environmental Crisses to Environmental Justice. Cambridge: Policy Press.

Friedlander, W. (1974) Introduction to Social Welfare. Prentice Hall. Inc. New Jersey.

Gray, M. (2005). Dilemmas of International Social Work Paradoxial Processes in Indigenous, Universalism and Imperialism. International Journal of Social Welfare. Vol 14 Issue 3 p 231 $-238$.

Gray, M.; John Coats; and Tiani Hetherington (2013). Environmental SocialWork. London: Routladge.

Luckett, Sidney (2004). Environmental Paradigms, Biodiversity Conservation, and Critical System Thinking. Systemic Practice and Action Research. Vol 17 Issue 5 p 511 $-534$.

McMichael, A. J. Et al. (2003). Climate Change and Human Health, Risk and Responses. WHO Library Cataloguing-in-Publication Data.

Purwowibowo (2014) Peran Pekerja Sosial Dalam Sistem Usaha Kesejahteraan Sosial di Era Millenium. Share (Social Work Journal). Vol 4 No. 2 Desember 2014.hal 198 - 210

Zastrow, C. (1996). Introduction to Social Work and Social Welfare. Brook I Cole Publishing Company. 